\title{
Negative Intergroup Contact and Radical Right-Wing Voting: The Moderating Roles of Personal and Collective Self-Efficacy
}

\author{
Tom Nijs iD \\ Utrecht University/Ercomer \\ Tobias H. Stark iD \\ Utrecht University/Ercomer \\ Maykel Verkuyten \\ Utrecht University/Ercomer
}

\begin{abstract}
This study examines whether negative contact with immigrants promotes voting for radical right-wing parties, to what extent this relationship can be explained by feelings of outgroup threat, and whether this relationship depends on perceived personal and collective self-efficacy. Hypotheses were tested among 630 native Dutch respondents, mainly living in multicultural neighborhoods. The results show that negative contact with immigrants is associated with feelings of personal (egocentric) and group (sociotropic) threat, and both these feelings, in turn, are associated with radical right-wing voting. However, negative intergroup contact is less strongly related to egocentric threat when individuals feel able to personally address negative situations with other people (personal self-efficacy). Furthermore, the findings suggest that negative intergroup contact is less strongly related to sociotropic threat when individuals believe that people in their neighborhood are able to collectively address some negative situations (collective self-efficacy).
\end{abstract}

KEY WORDS: collective self-efficacy, ethnic threat, negative intergroup contact, personal self-efficacy, radical right-wing voting

Interviews with voters for the radical right Dutch Party for Freedom (PVV) show that they "mention only one overwhelming reason to vote for the PVV: negative experiences with foreigners" (Aalberts, 2012, p. 157). Although research has revealed various determinants of radical right-wing voting, the importance of negative intergroup contact for this voting has not yet been studied systematically. Additionally, research on intergroup contact has shown that negative contact has a negative impact on outgroup attitudes (Barlow et al., 2012; Graf, Paolini, \& Rubin, 2014), but it has not considered radical right-wing voting.

The current study examined why and under what conditions negative contact with immigrants is related to radical right-wing voting intentions among the native Dutch. To answer the "why" question, we tested whether perceived threat to the self ("egocentric threat") and to the ingroup ("sociotropic threat") mediate the effect of negative contact on the intention to vote for a radical right-wing 
party. Negative intergroup contact is a central determinant of feelings of ethnic threat (Aberson \& Gaffney, 2009; Corenblum \& Stephan, 2001; Stephan, 2014; Stephan et al., 2002), and radical rightwing parties present themselves as protecting the native population against immigrants and ethnic minorities (Green, Sarrasin, Baur, \& Fasel, 2016; Lubbers \& Scheepers, 2000; Lucassen \& Lubbers, 2012; Werts, Scheepers, \& Lubbers, 2012).

In culturally diverse societies, people can have negative intergroup contact experiences (Barlow et al., 2012; Graf et al., 2014), but not all of these people vote for a radical right-wing party. To explore under what conditions negative contact is related to radical right-wing voting intentions, we tested whether feelings of self-efficacy moderate this relationship. People may perceive less threat to themselves if they feel able to personally address negative situations with other people (personal self-efficacy), and they may perceive less threat to their ingroup if they believe that their community is able to address such negative situations (collective self-efficacy). The current study focused on voting intentions rather than actual voting behavior, and although both strongly overlap (Granberg \& Holmberg, 1990), the results should be considered with a grain of salt because reports of voting intentions may be affected by socially desirable responding.

\section{Explaining Radical Right-Wing Voting}

Existing accounts for the electoral success of radical right-wing parties can broadly be categorized into supply-side and demand-side explanations (Mudde, 2007; Rydgren, 2007). Supply-side explanations concern party characteristics and the political and cultural context in which a rightwing party operates (Rydgren, 2007). Sociocultural cleavages, media coverage of political issues, the electoral system, party organization and leadership, and the way established parties deal with the rise of radical right-wing parties can all affect the electoral success of these parties (Mudde, 2007; Rydgren, 2007).

Demand-side explanations concern attitudes, interests, and preferences of individual voters which explain why some are more inclined to vote for a radical right-wing party than others. These explanations include nationalistic feelings (Lubbers \& Coenders, 2017), right-wing authoritarianism (Mudde, 2007), and euroskepticism (Lubbers \& Coenders, 2017; Mudde, 2010). Moreover, the populist antiestablishment rhetoric of radical right-wing parties attracts the politically dissatisfied and alienated electorate (Norris, 2005; Rydgren, 2007).

However, the most important demand-side explanation of voting for the radical right is anti-immigrant attitudes (Lubbers, Gijsberts, \& Scheepers, 2002; Lubbers \& Scheepers, 2000; Norris, 2005; Rydgren, 2008; Van Der Brug, Fennema, \& Tillie, 2000). Immigration is found to be the key issue of radical right-wing parties (Fennema, 1997; Ivarsflaten, 2008; Mudde, 2007), and Ivarsflaten (2008) even concluded that grievance over immigration is the only issue that unites all successful radical right-wing parties. The European radical right argues for drastic reductions in immigration and immigration stops, and these parties are therefore appealing to those who hold negative attitudes towards immigration and immigrants (Rydgren, 2008).

Negative interethnic contact experiences has emerged as an important explanation of ethnic prejudice in social psychology (Barlow et al., 2012; Dhont \& Van Hiel, 2009; Graf et al., 2014; Laurence, Schmid, \& Hewstone, 2017; Paolini, Harwood, \& Rubin, 2010; Stephan et al., 2002; Wölfer et al., 2017). Some people may perceive such negative encounters as a direct consequence of increasing cultural diversity, and these encounters might therefore increase the attraction of radical right-wing parties. These parties promise to restrict or even reverse immigration, which should reduce the likelihood of future negative encounters with immigrants. Thus, those who have experienced negative contact with immigrants may be more attracted and responsive to the anti-immigrant message of 
these parties making negative intergroup contact an important demand-side explanation for radical right-wing voting. Therefore, we hypothesize that:

H1: The more negative intergroup contact people have, the higher their intention to vote for a radical right-wing party.

\section{Feelings of Ethnic Threat}

Negative intergroup contact is one of the main causes of feelings of egocentric and sociotropic threat (Aberson \& Gaffney, 2009; Corenblum \& Stephan, 2001; Stephan, 2014; Stephan et al., 2002). Negative contact experiences are likely to lead to feelings of threat to the self that involve feeling apprehensive, distressed, and anxious about interaction outcomes and future interactions with outgroup members (Stephan, 2014). It may also lead to feelings of threat to the ingroup because these experiences can be seen as resulting from intergroup differences in norms, values, and interests (Stephan et al., 2002). Moreover, negative contact experiences, such as harassment or robbery, may lead to generalized associations of immigrants with violence and criminality that threaten the physical well-being of oneself and the ingroup.

Radical right-wing parties present themselves as protecting people against threats from immigrants, and they claim to serve the interest of the native population (Lucassen \& Lubbers, 2012). They link immigrants to a variety of societal problems (Werts et al., 2012), and their campaigns and discourse depict immigrants as a threat to the nation's economy, culture, and security (Green et al., 2016). These parties present migration restriction as a solution to the problems people face and therefore are attractive for people who feel threatened by immigrants. Therefore, we expect that:

$H 2 a$ : the relationship between negative intergroup contact and the intention to vote for a radical right-wing party is mediated by feelings of sociotropic threat.

$H 2 b$ : the relationship between negative intergroup contact and the intention to vote for a radical right-wing party is mediated by feelings of egocentric threat.

\section{The Role of Personal Self-Efficacy}

A study conducted by Hooghuis and Bank (2009) showed that $35 \%$ of a representative sample of the Dutch electorate reported negative contact experiences with immigrants in the past year but a far lower percentage voted for the PVV (17\%). This indicates that negative contact does not simply lead to radical right-wing voting. One likely moderating factor is personal self-efficacy which is conceptualized as a domain-specific ability belief (Bandura, 2006; Sherer et al., 1982; Zimmerman, 2000). Consistent with this approach, we examined personal self-efficacy as the belief in one's capabilities to address negative situations with other people. Some scholars have studied different forms of efficacy in relation to negative interpersonal situations (Mazziotta, Mummendey, \& Wright, 2011; Sampson, Raudenbush, \& Earls, 1997; Sharkey, 2006; Steenbeek \& Schutjens, 2014; Ufkes, 2010), but no study has examined the moderating role of personal self-efficacy beliefs in the relation between negative intergroup contact and intergroup outcomes.

Negative intergroup experiences might not, or less strongly, relate to feelings of egocentric threat when a person has a relatively high sense of personal self-efficacy. Individuals who have the feeling that they themselves are able to address negative situations with other people might consider a negative contact experience challenging rather than threatening. Research on perceived discrimination 
has shown that these negative experiences can be perceived as threatening or rather as challenging (Scheepers, 2013). And research on economic problems and health has found that difficult financial circumstances are less strongly related to negative health outcomes when people feel able to solve their problems and appraise economic hardship as challenging rather than as threatening (Lachman \& Weaver, 1998; Pudrovska, Schieman, Pearlin, \& Nguyen, 2005). Similarly, threatening circumstances such as increased likelihood of a terrorist attack are found to be less strongly related to prejudice when people perceive high feelings of control (Greenaway, Louis, Hornsey, \& Jones, 2014). Thus, we hypothesize that:

H3: the relationship between negative intergroup contact and egocentric threat is less strong for individuals with relatively high personal self-efficacy.

Personal self-efficacy should not affect the relationship between negative intergroup contact and sociotropic threat. A large social psychological literature has demonstrated that perceptions, feelings, and behaviors on the personal level (personal self) and on the group level (collective self) involve different psychological processes (e.g., Ellemers, 2012; Xiao, Coppin, \& Van Bavel, 2016). Feeling able to personally address negative situations does not have to imply that perceived threat at the level of the group is reduced. For example, a high sense of personal self-efficacy may prevent that negative intergroup contact leads to feeling apprehensive, distressed, and uneasy in personal interactions with immigrants, but it may not prevent the perception that the interests and identity of the ingroup are threatened by immigrants.

\section{The Role of Collective Self-Efficacy}

Whether negative intergroup contact is related to feelings of sociotropic threat might depend on the perception that one's own community can address negative situations with other people. Collective self-efficacy of neighbors has been found to reduce neighborhood crime, violence, and delinquency (Morenoff, Sampson, \& Raudenbush, 2001; Sampson et al., 1997). Additionally, the perception of collective self-efficacy has been found to be related to better social integration, lower perceived disorder, and less fear of crime (Gibson, Zhao, Lovrich, \& Gaffney, 2002). Collective self-efficacy may likewise weaken the relationship between negative intergroup contact experiences and feelings of sociotropic threat. People may feel less threat to their group if they think that their community is able and likely to address negative situations. Therefore, we hypothesize that:

H4: the relationship between negative intergroup contact and sociotropic threat is less strong for individuals with relatively high perceived collective self-efficacy.

In contrast, collective self-efficacy should not moderate the relationship between negative intergroup contact and egocentric threat. If people believe that ingroup members are able and willing to address negative situations, they might still worry, fear, and feel awkward in personal intergroup interactions.

\section{Method}

\section{Sample}

Data from an online survey conducted by the Verwey-Jonker Institute in June 2016 was used to test the hypotheses. The data were collected among Dutch natives living in the five biggest cities of 
the Netherlands (i.e., Amsterdam, Rotterdam, Utrecht, The Hague, and Eindhoven). In total, 850 respondents who all had parents born in the Netherlands took part in the survey. The analyses were restricted to the subsample of respondents who indicated to experience intergroup contact with immigrants at least once in the past year $(N=635)$. Only these people can feel egocentric threat through intergroup contact experiences and base their voting decision on such experiences. Three additional respondents were excluded from the sample because they did not answer any relevant question, and two respondents were excluded because they provided inconsistent answers to two questions that concerned voting intentions. ${ }^{1}$

Respondents were recruited via the opt-in online panel PanelClix (2016). They were invited to participate in the study by a general email and could participate by logging into a router system. Invitations were sent to ensure representativeness of the sample for gender, age, and education level of the population living in the five cities. People living in multicultural neighborhoods (with more than $50 \%$ non-Western immigrants and in Eindhoven, with more than $25 \%$ non-Western immigrants) were oversampled. The age of the respondents ranged from 18 to $80(M=45.25, S D=16.00)$ and $50 \%$ were female. Twenty percent of the sample was low educated (primary school, VMBO/MAVO, or LBO), $45 \%$ medium educated (MBO, HAVO, or VWO), and $35 \%$ high educated (HBO or university). Twenty-two percent was from Amsterdam, 27\% from Rotterdam, 18\% from Utrecht, 20\% from The Hague, and 13\% from Eindhoven. Finally, $10 \%$ of the respondents lived in neighborhoods with less than $10 \%$ non-Western immigrants, whereas $27 \%$ of the respondents lived in neighborhoods with more than $50 \%$ non-Western immigrants.

\section{Measures}

Likelihood to vote $P V V$. The dependent variable was measured by the question "How likely is it that you will vote for the PVV? Please, indicate this with a percentage." Respondents could indicate a number between 0 and 100 using a slider. This continuous measure was not normally distributed (skewness $=1.07$; kurtosis $=-.48$; Shapiro-Wilk $(595)=.70, p<.001$ ). Sixty-five percent of the respondents reported either 0 or 100 . Therefore, this continuous scale was transformed into a 7-point ordinal scale. People who indicated $0 \%$ were coded 1 (54\% of the respondents), people who indicated $1-20 \%$ were coded 2 (12\% of the respondents), people who indicated $21-40 \%$ were coded 3 (5\% of the respondents), people who indicated $41-60 \%$ were coded 4 ( $8 \%$ of the respondents), people who indicated $61-80 \%$ were coded 5 (6\% of the respondents), people who indicated $81-99 \%$ were coded 6 (4\% of the respondents), and people who indicated $100 \%$ were coded 7 (11\% of the respondents). ${ }^{2}$ Thirty-five respondents had missing values on this indicator because they stopped completing the questionnaire before reaching this question.

Negative intergroup contact. The independent variable was measured using a count variable. The exact wording of the instruction was "Can you indicate for the following negative situations in your neighborhood whether you have ever experienced these personally, have seen them happen, or have heard about them from others? It concerns situations caused by people from other cultures. You can tick more than one answer category per situation. For example, it could be that you have experienced one situation personally, but also have heard about it from others. In that case, tick both boxes." This means that three separate questions were answered in one response matrix. Respondents

\footnotetext{
${ }^{1}$ Respondents were asked "What would you vote if there were national parliamentary elections today?" and "How big is the chance that you will vote for the PVV? Indicate this with a percentage." One respondent answered "PVV" to the first question and indicated " $1 \%$ " in the second question. One respondent answered "VVD" (another political party) to the first question and indicated " $100 \%$ " in the second question.

${ }^{2}$ In a robustness check, this variable was recoded into a 3 -point ordinal scale $(1=0 \%$ chance; $2=1-99 \%$ chance; $3=100 \%$ chance). This coding did not affect the directions and significance levels of all associations in the moderated mediation model.
} 
were presented with nine different negative situations (e.g., "hindrance caused by loitering youth," "noise nuisance," "violence or molestation"; see Appendix S1 in the online supporting information for all items). The respondents could indicate whether they had personally experienced this (1) or not (0), and their answers were summed up $(0=$ no negative contact experience, $9=$ all possible negative contact situations). Answers indicating that respondents had seen the negative situations happen or had heard about them were not used in the final model. ${ }^{3}$

Sociotropic threat. The mediator sociotropic threat was measured with eight items based on previous research in the Netherlands (Velasco González, Verkuyten, Weesie, \& Poppe, 2008). The items tapped into feelings of symbolic threat (e.g., "Dutch norms and values are being threatened because of the presence of people from other cultures"), realistic economic threat (e.g., "Because of the presence of people from other cultures it is more difficult for Dutch natives to find a job"), and physical threat (e.g., "The presence of people from other cultures leads to an increase in crime"). All items were measured on a 5-point scale ranging from 1 (strongly disagree) to 5 (strongly agree). Ten respondents had missing values on this indicator because they stopped completing the questionnaire before reaching these questions, and eight had missing values because they responded with "Don't know/no opinion" on all items.

Egocentric threat. Egocentric threat was measured with 12 items based on the measure of intergroup anxiety by Stephan, Ybarra, and Bachman (1999). Respondents were asked "When you are having contact with neighbors from other cultures, how do you feel about that? Report a number between 1 and 10, in which 1 means that this feeling is not at all applicable and 10 means this feeling is highly applicable." Respondents were presented with six positive emotions (e.g., confident, safe) and six negative emotions (e.g., worried, awkward).

Perceived collective self-efficacy. The moderator perceived collective self-efficacy was measured with five items based on the informal social control scale of Sampson and colleagues (1997). Respondents were asked "how likely is it that your neighbors do something about the following situations?" The five situations ranged from "when a neighbor is playing loud music at night" to "when a fight starts in the street" (see Appendix S1 in the online supporting information for all items). All items were measured on a 5-point scale ranging from 1 (very unlikely) to 5 (very likely). Seven respondents had missing values on this indicator because they stopped completing the questionnaire before reaching these questions, and 44 respondents had missing values because they responded with "Don't know/no opinion" on all items.

Perceived personal self-efficacy. Personal self-efficacy was also measured with five items. Respondents were asked "do you think that you are able to personally do something about the following situations?" The five situations were similar to those for collective self-efficacy and were measured with the same 5-point scale (see Appendix S1 in the online supporting information). The measure was based on the informal social-control scale of Sampson and colleagues (1997) and on Bandura's (2006) instruction on how to construct self-efficacy scales. In line with his instructions, the scale measured perceived personal capabilities to address negative interpersonal situations with other people in the neighborhood. Moreover, in order to avoid ceiling effects, the items had a gradation of seriousness of the situational challenges (Bandura, 2006). Four respondents had missing values on this indicator because they stopped completing the questionnaire before reaching the questions and six had missing values because they responded with "Don't know/no opinion" on all items.

Control variables. The analysis controlled for some potentially confounding variables, namely gender, age (in years), education level, city of residence, and positive intergroup contact. Education level was categorized as low, medium, and high educated. The city of residence was included as a

\footnotetext{
${ }^{3}$ In a robustness check, negative extended contact (heard about it) and negative vicarious contact (seen it happen) were included as control variables, and this did not change the relationships between the concepts in the model. See Table S1 in Appendix S2 in the online supporting information.
} 
control (i.e., Amsterdam, Rotterdam, Utrecht, The Hague, and Eindhoven), since the cities differ significantly in demographics and ethnic composition (Entzinger \& Scheffer, 2012) and, therefore, may influence all variables in the model. Positive intergroup contact was measured in a similar way as negative intergroup contact. Respondents were introduced to six different positive-contact situations with people from other cultures in their neighborhood and were asked whether they had personally experienced this contact. The items were summated leading to a score between 0 and 6 . Two respondents had missing values on this indicator because they stopped completing the questionnaire before reaching this question.

\section{Analysis}

Relations between latent variables were examined using structural equation modeling in Mplus Version 7.3., which allows accounting for measurement error (McCoach, Black, \& O'Connell, 2007). Sociotropic and egocentric threat, perceived collective self-efficacy, and personal self-efficacy were latent variables, each measured with multiple indicators. Ordinary least squares regression analysis was used to predict the indicators of both types of threat. Ordinal regression analyses were performed to predict respondents' likelihood to vote for the PVV. Models were fitted using full-information maximum likelihood (Muthén \& Muthén, 2010). This estimation method allows missing values in dependent variables, assuming missingness at random. Multiple imputation was performed to account for missingness on the exogenous variables, using a Markov Chain Monte Carlo (MCMC) simulation, using 10 replications (Asparouhov \& Muthén, 2010).

Clustering of respondents in neighborhoods (four-digit postal-code areas) was taken into account in all statistical models to avoid biased standard errors. Respondents from the same neighborhood may be more similar than respondents from different neighborhoods, which violates the assumption of independence of observations (Hox, 2010). The intraclass correlations ${ }^{4}$ of most of the endogenous variables treating four-digit postal-code areas as second-level units were small (Hox, 2010): .024 for likelihood to vote PVV; .020 to .101 for all items of sociotropic threat; and .002 to .042 for all items of egocentric threat. The nested structure was still taken into account in all analyses by using the clustering option in Mplus. There were 208 four-digit postal-code areas used as clusters with the number of respondents within a cluster ranging from 1 to $18 .^{5}$ Due to clustering, bootstrapping was not available to test for mediation, but MLR was employed to deal with the nonnormal distribution of endogenous variables.

\section{Results}

\section{Measurement Model}

Confirmatory factor analysis was used to test whether the items measuring sociotropic and egocentric threat, personal self-efficacy, and collective self-efficacy were assessing separate latent constructs. The expected four-factor model fitted the data significantly better than one-, two-, or three-factor models (see Appendix S3 in the online supporting information for all fit statistics). Yet, the model fit of the four-factor model was below conventional rules of thumb $(C F I=.786, R M S E A=$ $.095, S R M R=.082$ ). Modification indices suggested better fit of a model in which all positive

\footnotetext{
${ }^{4}$ The intraclass correlation is calculated by dividing the between (neighborhood) level variance by the sum of between and within (individual) level variance.

${ }^{5}$ Since we do not test variables at the second level but only account for the nested structure, there is no requirement for a minimum of units per cluster.
} 
emotions of egocentric threat loaded on one factor and all negative emotions of egocentric threat loaded on another factor. This is a well-documented sign of a method bias according to which negatively worded (reverse-coded) questions in a larger item-battery can produce an artifactual response factor because some respondents do not pay sufficient attention to the reversely worded questions (Podsakoff, MacKenzie, Lee, \& Podsakoff, 2003). This method bias is often captured by allowing the positively worded items to correlate with each other and the negatively worded items to also correlate with each other. However, the more parsimonious approach is to use a common method factor that requires fewer degrees of freedom (Podsakoff et al., 2003). Accordingly, all positive and negative emotion items were specified to freely load onto one egocentric threat factor ${ }^{6}$ and, to account for the method bias, all items also loaded on a common method factor. The loadings on the common-method factor were constrained to be equal, and this factor was constrained to be uncorrelated with all other factors in the model (Kenny, 2012; Saris \& Aalberts, 2003). This led to an acceptable model fit $(C F I=.912, R M S E A=.061, S R M R=.046)$. All indicators loaded significantly on the respective factors. The scales for sociotropic threat (Cronbach's $\alpha=.94$ ), personal self-efficacy $(\alpha=.85)$, and collective self-efficacy ( $\alpha=.93)$ were highly reliable. The reliability of the scale for egocentric threat was lower $(\alpha=.60)$, but we decided to leave all 12 items in because this scale is validated in existing literature and all items are meant to equally represent the variety of possible feelings experienced in interactions (Stephan et al., 1999).

In the final model, personal self-efficacy and collective self-efficacy were treated as manifest variables (mean scores) because model fitting with two interactions between latent constructs posed unsurmountable numerical problems for Mplus. ${ }^{7}$ A model with egocentric and sociotropic threat as latent factors and personal self-efficacy and collective self-efficacy as manifest variables had an acceptable fit $(C F I=.921, R M S E A=.070, S R M R=.041)$.

\section{Descriptive Findings}

The descriptives of all latent and manifest variables are presented in Table 1. On average, respondents reported having had two negative intergroup contact experiences, most often (45.5\%) related to noise nuisance from people from other cultures. In total, 34.8\% indicated to have experienced none of the negative contact situations. Negative and positive contact were positively but weakly correlated $(r=.141, p<.001)$, which suggests that people who experienced more positive intergroup contact tended to also experience more negative intergroup contact.

\section{Predicting Radical Right-Wing Voting Intentions}

In a first model, the likelihood to vote PVV was regressed on negative intergroup contact. Sociotropic and egocentric threat were included as mediators of this relationship and the covariance between the residuals of these mediators was freed. The total effect, including direct and indirect effects, indicates a substantial positive association between negative intergroup contact and the likelihood to vote PVV $(\beta=.257, S E=.043, p<.001)$. Thus, and in line with Hypothesis 1 , the more

\footnotetext{
${ }^{6}$ The loading of the first item was constraint to 1 to specify the metric of the latent variable.

${ }^{7}$ Mean scores were constructed by dividing the sum of the nonmissing values by the number of nonmissing items. The high reliability of personal self-efficacy $(\alpha=.85)$ and collective self-efficacy $(\alpha=.93)$ suggested that treating the moderators as manifest was reasonable. In supplementary analyses, a model with only the interaction of personal self-efficacy, treated as a latent construct, with negative contact was fitted. The directions and strengths of the effects in this model did not differ from using a manifest score for efficacy (see Table S2 in Appendix S2 in the online supporting information). Similarly, a model with only the interaction of collective self-efficacy, treated as a latent construct, with negative contact showed that the directions and strengths of the effects in this model were similar to a model with only the interaction of collective selfefficacy as a manifest variable (see Table S3 in Appendix S2).
} 


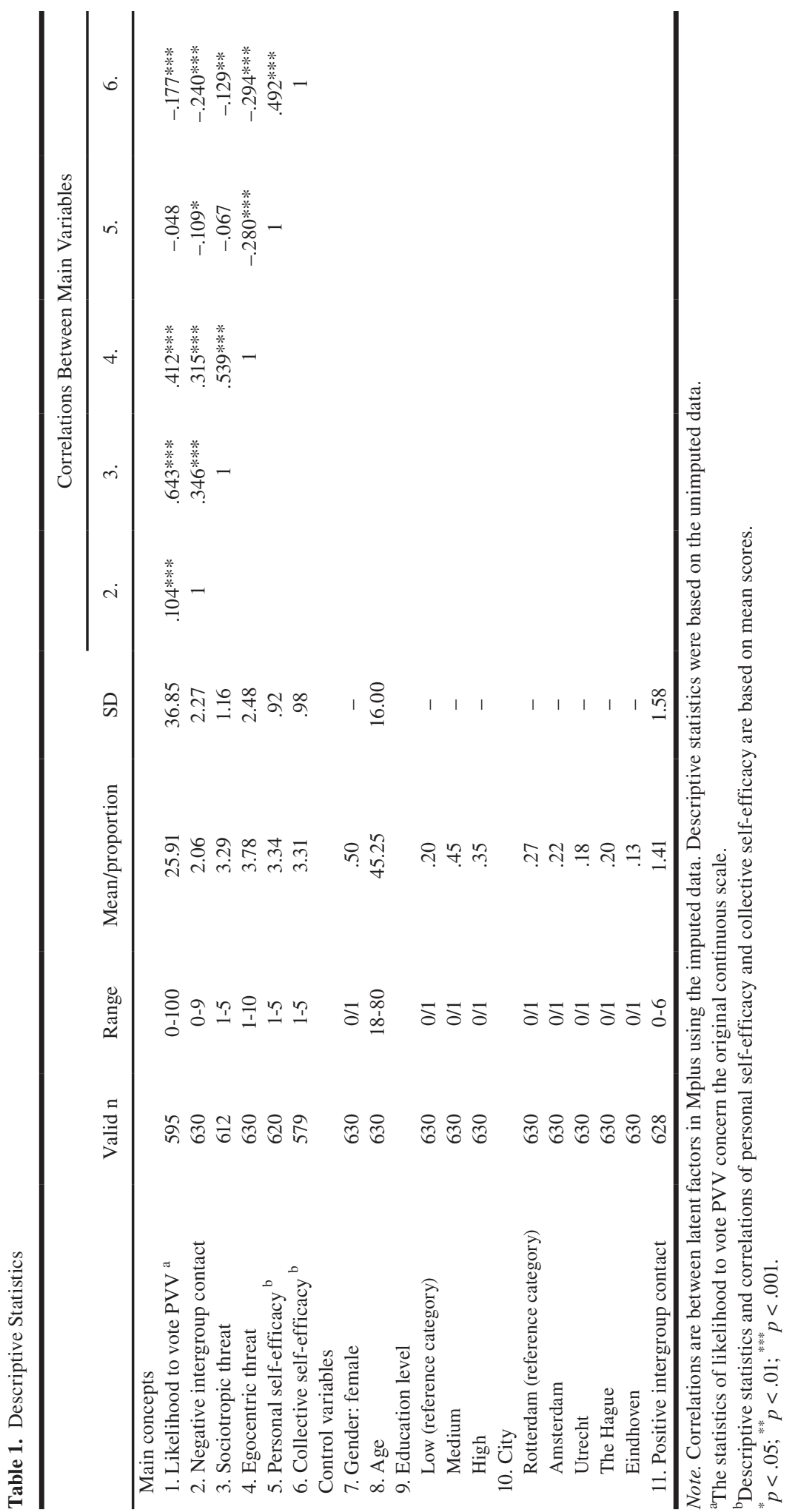


negative intergroup contact respondents had, the higher their self-reported likelihood to vote for the PVV.

The indirect effects showed that the association between negative intergroup contact and the likelihood to vote PVV was mediated by higher sociotropic threat $(\beta=.213, S E=.029, p<.001)$ and higher egocentric threat $(\beta=.038, S E=.017, p=.023)$. When the mediators were included in the model, there was no longer a direct effect of negative intergroup contact on the likelihood to vote PVV ( $\beta=.009, S E=.037, p=.815)$. These findings suggest full mediation and are in line with Hypotheses $2 \mathrm{a}$ and $2 \mathrm{~b}$. An $R^{2}$ of .491 for the dependent variable likelihood to vote PVV indicates that almost half of the variation in voting intention was explained by the independent variable, mediators, and control variables in the model.

People who experienced positive intergroup contact had a lower self-reported likelihood to vote for the PVV $(\beta=-.182, S E=.045, p<.001)$ and indirect effects showed that this negative association was mediated by lower sociotropic threat $(\beta=-.158, S E=.025, p<.001)$ and lower egocentric threat $(\beta=-.037, S E=.016, p=.023$ ) (for all results, including coefficients of control variables, see Appendix S4 in the online supporting information).

In a second model, the main and moderating effects of personal self-efficacy on the relationship between negative intergroup contact and egocentric threat and the main and moderating effects of collective self-efficacy on the relationship between negative intergroup contact and sociotropic threat were added (see Figure 1).

The association between negative intergroup contact and egocentric threat was significantly moderated by personal self-efficacy $(\beta=-.305, S E=.116, p=.009)$. As expected (H3), simple slope analyses indicated that this association was stronger for respondents who had a relatively low perception of personal self-efficacy (i.e., one standard deviation below the mean: $B=.338, S E=.037 p$ $<.001$ ), compared to participants with a relatively high perception of personal self-efficacy (i.e., one standard deviation above the mean: $B=.202, S E=.046 p<.001)$. In other words, higher personal self-efficacy weakened the relationship between negative intergroup contact and egocentric threat, but without fully buffering this relationship.

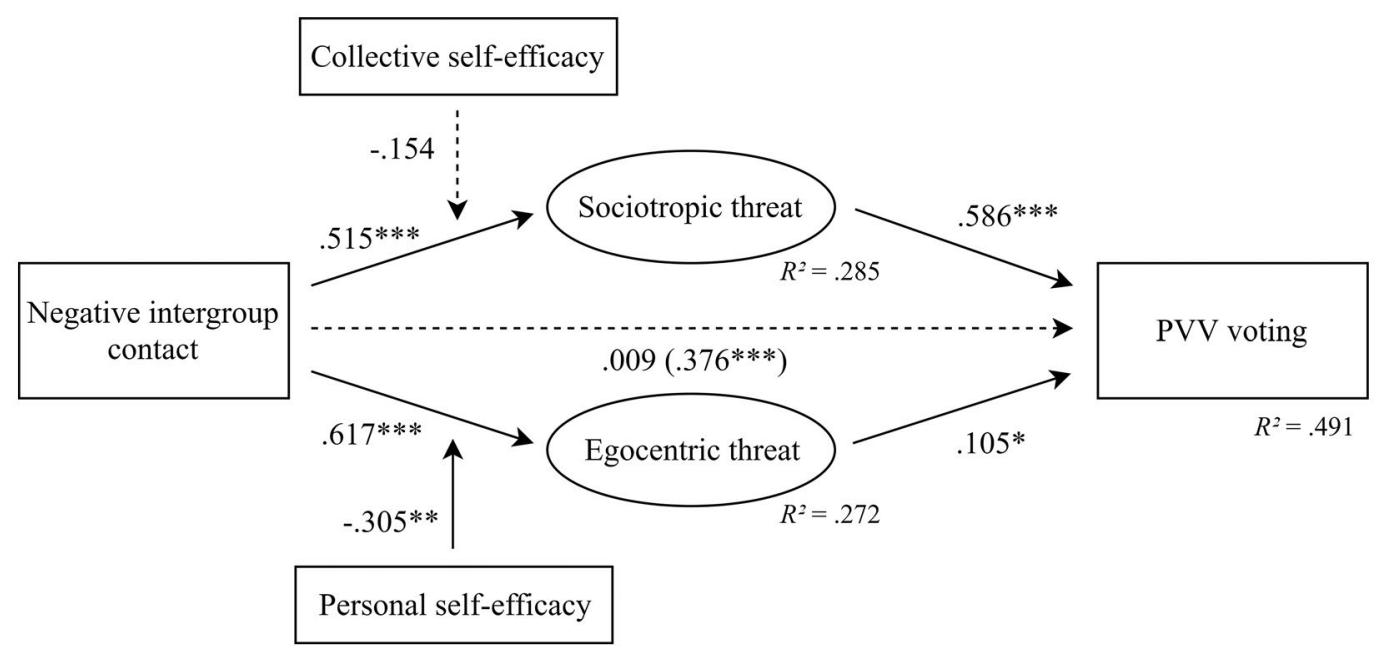

Figure 1. Standardized coefficients of the main paths of a structural equation model $(N=630)$. The coefficient in parenthesis is the total effect (direct and indirect effect). Control variables are not reported and nonsignificant paths are presented as dashed lines. Collective self-efficacy and personal self-efficacy were treated as manifest mean scores. $* p<.05 ; * *<.01 ; * * *<.001$. 
Unexpectedly (H4), collective self-efficacy did not significantly moderate the association between negative intergroup contact and sociotropic threat $(\beta=-.154, S E=.095, p=.106)$. Thus the association between negative intergroup contact and sociotropic threat did not depend on the perception that one's neighbors are willing to address negative situations. ${ }^{8}$

\section{Robustness Checks}

Three robustness checks were performed. First, we examined whether the type of negative contact experience affected the moderating roles of personal self-efficacy and collective self-efficacy. Some contact experiences that were asked about can more easily be addressed (i.e., "hindrance caused by loitering youth," "noise nuisance," "deterioration of public space," "harassing, insulting or calling names"), whereas other contact experiences are more outside of people's direct control or involve severe offenses (i.e., "hindrance in traffic," "robbery or burglary," "demolition or daubing," "violence or molestation"). The two forms of self-efficacy might be more relevant for the former types of negative contact than the latter. An analysis in which only the four negative contact experiences that can more easily be addressed were included showed that the association between negative intergroup contact and sociotropic threat $(\beta=.564, S E=.097, p<.001)$ and the association between negative intergroup contact and egocentric threat $(\beta=.611, S E=.101, p=.001)$ were similar to the previous model. Moreover, the moderation of personal self-efficacy on the relationship between negative contact and egocentric threat was similar as in the previous model $(\beta=-303, S E=.111$, $p=.006$ ). Additionally, in this analysis the association between negative intergroup contact and sociotropic threat was significantly moderated by collective self-efficacy $(\beta=-.210, S E=.096, p=.029)$. As expected (H4), simple slope analysis indicated that the association was stronger for low (i.e., one standard deviation below the mean: $B=.278, S E=.031, p<.001)$ compared to high perceived collective self-efficacy (i.e., one standard deviation above the mean: $B=.193, S E=.035, p<.001$ ).

A second robustness check explored the directions of the relations. The fit of the mediation model was compared to the fit of a model with alternative direction of influences in which sociotropic and egocentric threats predicted negative intergroup contact, which in turn predicted the likelihood to vote PVV. The Akaike Information Criterion (AIC) was substantially higher in this model, which indicates a worse fit. A chi-square test of model fit and incremental fit indices could not be obtained because numerical integration was required for the analyses (Muthén \& Muthén, 2010). Therefore, the models were compared when employing a WLSMV estimator. Our proposed model using this estimator showed an acceptable fit $\left(\chi^{2}(d f)=542.815(366), C F I=.946, R M S E A=.028\right)$, that was significantly better than a model with the alternative causal paths $\left(\Delta \chi^{2}(d f)=381.116(18)\right.$, $p<.001$ ) (see Table S1 in Appendix S5 in the online supporting information).

In a third robustness check, single items of four main explanations of radical right-wing voting (political dissatisfaction, authoritarianism, anti-EU attitudes, and nationalistic feelings) were added as control variables. Authoritarianism $(\beta=.117, S E=.045, p=.029)$ and anti-EU attitudes $(\beta=.188$, $S E=.055, p=.029)$ were both positively associated with the likelihood to vote PVV, while political dissatisfaction and nationalistic feelings were not significant independent correlates (see Table S3 in Appendix S5 in the online supporting information). Importantly, the positive relationship between negative intergroup contact and the likelihood to vote PVV remained and was significantly mediated by sociotropic threat $(\beta=.180, S E=.030, p<.001)$ and by egocentric threat $(\beta=.035, S E=.018$,

\footnotetext{
${ }^{8}$ Due to multicollinearity issues, it was not possible to include personal self-efficacy as a moderator of the relationship between negative intergroup contact and sociotropic threat or collective self-efficacy as a moderator of relationship between intergroup contact and egocentric threat. Neither of these moderators turned out to be significant in separate analyses in which only these interactions were added to the model (see Table S4 in Appendix S2).
} 
$p=.049$ ), which indicates that adding these explanations did not substantively change the relationships proposed and tested.

\section{Discussion}

Consistent with what voters of radical right-wing parties say in interviews (Aalberts, 2012), this study showed that more negative contact with immigrants is related to a stronger intention for radical right-wing voting. The association between negative intergroup contact and the likelihood to vote PVV could be explained by feelings of ethnic threat to the group and threat to the self. This is consistent with research showing that negative intergroup contact is an important antecedent of both sociotropic and egocentric threat (Aberson \& Gaffney, 2009; Corenblum \& Stephan, 2001; Stephan et al., 2002). Moreover, the findings are in line with studies demonstrating that people who experience realistic and symbolic threat are more likely to vote for radical right-wing parties (Green et al., 2016; Lucassen \& Lubbers, 2012; Werts et al., 2012).

The current study demonstrates, for the first time, that egocentric threat can explain radical right-wing voting intentions, independently of perceived sociotropic group. Furthermore, this is the first study to show that negative intergroup contact is less strongly associated with egocentric threat when people feel able to personally address negative situations with others. This result is consistent with Ufkes' (2010) proposition that the consequences of neighbor-to-neighbor conflict depend on how individuals perceive and handle such conflicts. Individuals may have experienced negative contact with immigrants but these experiences are less likely to lead to feelings of threat when people feel able to personally address negative interpersonal situations.

Additionally, we found some evidence for the proposition that negative intergroup contact may be less strongly associated with perceived sociotropic threat when people believe that their neighbors are likely to address negative situations. Previous research has shown that actual support can explain neighborhood level phenomena such as crime or violence (Morenoff et al., 2001; Sampson et al., 1997). Our findings suggest that the construct of perceived collective self-efficacy is also relevant for understanding feelings of sociotropic threat. However, the results indicate that this is only true for negative contact situations that can more easily be addressed by people themselves such as noise nuisance, and not for contact situations that are more beyond people's control such as robbery or violence.

\section{Measuring Negative Contact and Limitations}

Most previous research has measured negative contact by asking respondents to indicate how many negative contact experiences they have had (e.g., Barlow et al., 2012) or by asking about the quantity and quality of intergroup contact (e.g., Khan \& Pedersen, 2012; Rohmann, Florack, \& Piontkowski, 2006). These overall measures of negative intergroup contact may suffer from memory errors (Stone, Bachrach, Jobe, Kurtzman, \& Cain, 1999) and socially desirable responding (Donaldson \& Grant-Vallone, 2002) and may therefore be sensitive to reverse causality. For example, respondents who experience more ethnic threat might be more likely to remember negative intergroup contacts or interpret situations in a negative way. Thus, negative contact may not lead to higher perceptions of threat but rather these perceptions may lead to more negative intergroup contact.

We tried to address some of these problems by presenting respondents with different concrete examples of negative contact experiences that can occur in their neighborhood. This approach helps people to remember specific experiences they might not have thought about otherwise. Moreover, the respondents were asked whether they have personally experienced negative situations, whether they have seen them happen, or have heard about them. This may have led to the realization that a 
negative experience that respondents had in mind was actually something they did not experiences themselves. Furthermore, the focus on examples in the neighborhood context may have helped people to think about concrete negative contact experiences. All this is likely to reduce memory errors and the likelihood of reverse causality but the use of cross-sectional data still prevents conclusions about the direction of influence. People who prefer radical right-wing parties or who feel threatened by immigrants may also justify these preferences and feelings by reporting negative contact experiences. Yet a model with an alternative causal direction fitted the data significantly worse than our proposed model. However, longitudinal data are needed to draw stronger conclusions about the direction of (mutual) influences (Pettigrew \& Tropp, 2006). Such data would also allow examining the possibility that perceptions of personal self-efficacy and collective self-efficacy influence the quality of intergroup contact. People who feel able to address challenging situations may not experience such situations as negative, and this might explain why individuals with higher personal self-efficacy and especially collective self-efficacy reported significantly less negative intergroup contact.

Another limitation is that our collective self-efficacy measure focused on the level of the neighborhood whereas the ingroup in the threat questions concerned the native population as a whole. The feeling that the native population is being threatened may be perceived as being outside control of people in a neighborhood. Therefore, negative contact might still be associated to sociotropic threat, despite a feeling of local collective efficacy. This might explain why collective self-efficacy did not moderate the effect of negative contact in the main analysis. Another explanation for this might be that the measure of collective self-efficacy focused more on the perceived willingness to do something about the situation whereas the measure of personal self-efficacy was more concerned with individuals' perceived ability. Future research could investigate feelings of collective self-efficacy by more explicitly focusing on the perceived ability and by considering threats at the level of the neighborhood (see Savelkoul, Laméris, \& Tolsma, 2017).

The present study does not allow making claims about the extent to which negative intergroup contact explains radical right-wing voting (intentions) over and above existing explanations. Yet, in a robustness check, measures of political dissatisfaction, authoritarianism, anti-EU attitudes, and nationalistic feelings (Lubbers \& Coenders, 2017; Mudde, 2007, 2010; Norris, 2005; Rydgren, 2007) were added as control variables, and this did not change the relationships found in the main analysis. In agreement with qualitative research (Aalberts, 2012), this suggests that negative intergroup contact adds explanatory value to our understanding of radical right-wing voting and therefore should be considered in future research.

\section{Conclusion}

This study indicates that when people living in ethnically diverse urban neighborhoods experience negative contact with immigrants, they are more likely to feel threatened and therefore have a stronger intention to vote for a radical right-wing party. However, this association is less strong if people either feel able to personally address such negative contact situations or if they think that their neighbors are likely to address such situations. Perceptions of personal self-efficacy and collective self-efficacy did not fully prevent, respectively, feelings of egocentric and sociotropic threat, but they reduced the associations considerably.

With increasing ethnic diversity in many urban neighborhoods, the chances for both negative as well as positive intergroup contact increase. Intergroup relations can be improved by positive contact but also by interventions that focus on increasing people's perceived efficacy as an individual person and as a neighborhood community. This might reduce the negative consequences of negative contact which is important in situations in which the actual reduction of negative contact is difficult. Evaluation studies show that perceptions of (collective) efficacy can be strengthened by neighborhood interventions (e.g., Berg, Coman, \& Schensul, 2009; Cerdá et al., 2012). The present 
research suggests that such interventions may be particularly useful when implemented in diverse neighborhoods.

\section{ACKNOWLEDGMENTS}

The authors thank Ron van Wonderen and Borja Martinovic for helpful comments on drafts of this article and the Verwey-Jonker Institute for making the data available. Correspondence concerning this article should be addressed to Tom Nijs, Utrecht University, Interdisciplinary Social Science, Padualaan 14, 3584 CH Utrecht, the Netherlands. Email: t.nijs@uu.nl

\section{REFERENCES}

Aalberts, C. (2012). Achter de PVV: Waarom burgers op Geert Wilders stemmen. Delft, Netherlands: Eburon Uitgeverij BV.

Aberson, C. L., \& Gaffney, A. M. (2009). An integrated threat model of explicit and implicit attitudes. European Journal of Social Psychology, 39(5), 808-830. https://doi.org/10.1002/ejsp.582

Asparouhov, T., \& Muthén, B. (2010). Multiple imputation with Mplus. MPlus Web Notes.

Bandura, A. (2006). Guide for constructing self-efficacy scales. In F. Pajares \& T. Urdan (Eds.), Self-efficacy beliefs of adolescents (Vol. 5, pp. 307-337). Greenwich, CT: Information Age.

Barlow, F. K., Paolini, S., Pedersen, A., Hornsey, M. J., Radke, H. R. M., Harwood, J., ... Sibley, C. G. (2012). The contact caveat: Negative contact predicts increased prejudice more than positive contact predicts reduced prejudice. Personality and Social Psychology Bulletin, 38(12), 1629-1643. https://doi.org/10.1177/0146167212457953

Berg, M., Coman, E., \& Schensul, J. J. (2009). Youth action research for prevention: A multi-level intervention designed to increase efficacy and empowerment among urban youth. American Journal of Community Psychology, 43(3), 345-359. https://doi.org/10.1007/s10464-009-9231-2

Cerdá, M., Morenoff, J. D., Hansen, B. B., Tessari Hicks, K. J., Duque, L. F., Restrepo, A., \& Diez-Roux, A. V. (2012). Reducing violence by transforming neighborhoods: A natural experiment in Medellín. Colombia. American Journal of Epidemiology, 175(10), 1045-1053. https://doi.org/10.1093/aje/kwr428

Corenblum, B., \& Stephan, W. G. (2001). White fears and native apprehensions: An integrated threat theory approach to intergroup attitudes. Canadian Journal of Behavioural Science / Revue canadienne des sciences du comportement, 33(4), 251-268. https://doi.org/10.1037/h0087147

Dhont, K., \& Van Hiel, A. (2009). We must not be enemies: Interracial contact and the reduction of prejudice among authoritarians. Personality and Individual Differences, 46(2), 172-177. https://doi.org/10.1016/j.paid.2008.09.022

Donaldson, S. I., \& Grant-Vallone, E. J. (2002). Understanding self-report bias in organizational behavior research. Journal of Business and Psychology, 17(2), 245-260. https://doi.org/10.1023/a:1019637632584

Ellemers, N. (2012). The group self. Science, 336(6083), 848-852.

Entzinger, H., \& Scheffer, P. (2012). De staat van integratie: Amsterdam en Rotterdam vergeleken: Gemeente Amsterdam, Gemeente Rotterdam.

Fennema, M. (1997). Some conceptual issues and problems in the comparison of anti-immigrant parties in Western Europe. Party Politics, 3(4), 473-492. https://doi.org/10.1177/1354068897003004002

Gibson, C. L., Zhao, J., Lovrich, N. P., \& Gaffney, M. J. (2002). Social integration, individual perceptions of collective efficacy, and fear of crime in three cities. Justice Quarterly, 19(3), 537-564. https://doi.org/10.1080/07418820200095341

Graf, S., Paolini, S., \& Rubin, M. (2014). Negative intergroup contact is more influential, but positive intergroup contact is more common: Assessing contact prominence and contact prevalence in five Central European countries. European Journal of Social Psychology, 44(6), 536-547. https://doi.org/10.1002/ejsp.2052

Granberg, D., \& Holmberg, S. (1990). The intention-behavior relationship among US and Swedish voters. Social Psychology Quarterly, 53(1), 44-54.

Green, E. G. T., Sarrasin, O., Baur, R., \& Fasel, N. (2016). From stigmatized immigrants to radical right voting: A multilevel study on the role of threat and contact. Political Psychology, 37(4), 465-480. https://doi.org/10.1111/pops.12290

Greenaway, K. H., Louis, W. R., Hornsey, M. J., \& Jones, J. M. (2014). Perceived control qualifies the effects of threat on prejudice. British Journal of Social Psychology, 53(3), 422-442. https://doi.org/10.1111/bjso.12049

Hooghuis, M., \& Bank, M. (2009). De PVV-stemmer: profiel, achtergrond en motieven [The PVV-voter: Profile, background and motives]. Synovate. Retrieved from https://docplayer.nl/11699029-De-pvv-stemmer-profiel-achtergrond-en-motieven-rapport.html

Hox, J. J. (2010). Multilevel analysis: Techniques and applications (2nd ed.). New York, NY: Routledge. 
Ivarsflaten, E. (2008). What unites right-wing populists in Western Europe?: Re-examining grievance mobilization models in seven successful cases. Comparative Political Studies, 41(1), 3-23. https://doi.org/10.1177/0010414006294168

Kenny, D. A. (2012, November 29, 2017). Multitrait Multimethod Matrix: Retrieved fromhttp://davidakenny.net/cm/mtmm. htm

Khan, S., \& Pedersen, A. (2012). Black African immigrants to Australia: Prejudice and the function of attitudes. Journal of Pacific Rim Psychology, 4(2), 116-129. https://doi.org/10.1375/prp.4.2.116

Lachman, M. E., \& Weaver, S. L. (1998). The sense of control as a moderator of social class differences in health and well-being. Journal of Personality and Social Psychology, 74(3), 763-773. https://doi.org/10.1037/0022-3514.74.3.763

Laurence, J., Schmid, K., \& Hewstone, M. (2017). Ethnic diversity, inter-group attitudes and countervailing pathways of positive and negative inter-group contact: An analysis across workplaces and neighbourhoods. Social Indicators Research. https://doi.org/10.1007/s11205-017-1570-z

Lubbers, M., \& Scheepers, P. (2000). Individual and contextual characteristics of the German extreme right-wing vote in the 1990s. A test of complementary theories. European Journal of Political Research, 38(1), 63-94. https://doi. org/10.1023/a: 1007015715758

Lubbers, M., \& Coenders, M. (2017). Nationalistic attitudes and voting for the radical right in Europe. European Union Politics, 18(1), 98-118. https://doi.org/10.1177/1465116516678932

Lubbers, M., Gijsberts, M., \& Scheepers, P. (2002). Extreme right-wing voting in Western Europe. European Journal of Political Research, 41(3), 345-378. https://doi.org/10.1111/1475-6765.00015

Lucassen, G., \& Lubbers, M. (2012). Who fears what? Explaining far-right-wing preference in Europe by distinguishing perceived cultural and economic ethnic threats. Comparative Political Studies, 45(5), 547-574. https://doi. org/10.1177/0010414011427851

Mazziotta, A., Mummendey, A., \& Wright, S. C. (2011). Vicarious intergroup contact effects: Applying social-cognitive theory to intergroup contact research. Group Processes \& Intergroup Relations, 14(2), 255-274. https://doi. org/10.1177/1368430210390533

McCoach, D. B., Black, A. C., \& O'Connell, A. A. (2007). Errors of inference in structural equation modeling. Psychology in the Schools, 44(5), 461-470. https://doi.org/10.1002/pits.20238

Morenoff, J. D., Sampson, R. J., \& Raudenbush, S. W. (2001). Neighborhood inequality, collective efficacy, and the spatial dynamics of urban violence. Criminology, 39(3), 517-558. https://doi.org/10.1111/j.1745-9125.2001.tb00932.x

Mudde, C. (2007). Populist radical right parties in Europe (Vol. 22). Cambridge, United Kingdom: Cambridge University Press.

Mudde, C. (2010). The populist radical right: A pathological normalcy. West European Politics, 33(6), 1167-1186. https://doi. org/10.1080/01402382.2010.508901

Muthén, L. K., \& Muthén, B. O. (2010). Mplus user's guide: Statistical analysis with latent variables: User's guide (Version 6). Los Angeles, CA: Muthén \& Muthén.

Norris, P. (2005). Radical right: Voters and parties in the electoral market. Cambridge, United Kingdom: Cambridge University Press.

PanelClix. (2016). Online market research: Panel book 2016. Retrieved from http://www.panelclix.nl/expertise/images/ panelbook.pdf

Paolini, S., Harwood, J., \& Rubin, M. (2010). Negative intergroup contact makes group memberships salient: Explaining why intergroup conflict endures. Personality and Social Psychology Bulletin, 36(12), 1723-1738. https://doi. org/10.1177/0146167210388667

Pettigrew, T. F., \& Tropp, L. R. (2006). A meta-analytic test of intergroup contact theory. Journal of Personality and Social Psychology, 90(5), 751.

Podsakoff, P. M., MacKenzie, S. B., Lee, J.-Y., \& Podsakoff, N. P. (2003). Common method biases in behavioral research: A critical review of the literature and recommended remedies. Journal of Applied Psychology, 88(5), 879-903. https://doi. org/10.1037/0021-9010.88.5.879

Pudrovska, T., Schieman, S., Pearlin, L. I., \& Nguyen, K. (2005). The sense of mastery as a mediator and moderator in the association between economic hardship and health in late life. Journal of Aging and Health, 17(5), 634-660. https://doi. org/10.1177/0898264305279874

Rohmann, A., Florack, A., \& Piontkowski, U. (2006). The role of discordant acculturation attitudes in perceived threat: An analysis of host and immigrant attitudes in Germany. International Journal of Intercultural Relations, 30(6), 683-702. https://doi.org/10.1016/j.ijintrel.2006.06.006

Rydgren, J. (2007). The sociology of the radical right. Annual Review of Sociology, 33(1), 241-262. https://doi.org/10.1146/ annurev.soc.33.040406.131752

Rydgren, J. (2008). Immigration sceptics, xenophobes or racists? Radical right-wing voting in six West European countries. European Journal of Political Research, 47(6), 737-765. https://doi.org/10.1111/j.1475-6765.2008.00784.x 
Sampson, R. J., Raudenbush, S. W., \& Earls, F. (1997). Neighborhoods and violent crime: A multilevel study of collective efficacy. Science, 277(5328), 918-924. https://doi.org/10.1126/science.277.5328.918

Saris, W. E., \& Aalberts, C. (2003). Different explanations for correlated disturbance terms in MTMM studies. Structural Equation Modeling: A Multidisciplinary Journal, 10(2), 193-213. https://doi.org/10.1207/s15328007sem1002_2

Savelkoul, M., Laméris, J., \& Tolsma, J. (2017). Neighbourhood ethnic composition and voting for the radical right in the Netherlands. The role of perceived neighbourhood threat and interethnic neighbourhood contact. European Sociological Review, 33(2), 209-224. https://doi.org/10.1093/esr/jcw055

Scheepers, D. (2013). Studying social identity-based threats and challenges using cardiovascular measures. In B. Derks, D. Scheepers, \& N. Ellemers (Eds.), Neuroscience of prejudice and intergroup relations (pp. 243-259). New York, NY: Psychology Press.

Sharkey, P. T. (2006). Navigating dangerous streets: The sources and consequences of street efficacy. American Sociological Review, 71(5), 826-846. https://doi.org/10.1177/000312240607100506

Sherer, M., Maddux, J. E., Mercandante, B., Prentice-Dunn, S., Jacobs, B., \& Rogers, R. W. (1982). The self-efficacy scale: Construction and validation. Psychological Reports, 51(2), 663-671. https://doi.org/10.2466/pr0.1982.51.2.663

Steenbeek, W., \& Schutjens, V. (2014). The willingness to intervene in problematic neighbourhood situations: A comparison of local entrepreneurs and (un-)employed residents. Tijdschrift voor economische en sociale geografie, 105(3), 349-357. https://doi.org/10.1111/tesg.12092

Stephan, W. G. (2014). Intergroup anxiety: Theory, research, and practice. Personality and Social Psychology Review, 18(3), 239-255. https://doi.org/10.1177/1088868314530518

Stephan, W. G., Ybarra, O., \& Bachman, G. (1999). Prejudice toward immigrants. Journal of Applied Social Psychology, 29(11), 2221-2237. https://doi.org/10.1111/j.1559-1816.1999.tb00107.x

Stephan, W. G., Boniecki, K. A., Ybarra, O., Bettencourt, A., Ervin, K. S., Jackson, L. A., ... Renfro, C. L. (2002). The role of threats in the racial attitudes of blacks and whites. Personality and Social Psychology Bulletin, 28(9), 1242-1254. https://doi.org/10.1177/01461672022812009

Stone, A. A., Bachrach, C. A., Jobe, J. B., Kurtzman, H. S., \& Cain, V. S. (1999). The science of self-report: Implications for research and practice. London, United Kingdom: Psychology Press.

Ufkes, E. G. (2010). Neighbor-to-neighbor conflicts in multicultural neighborhoods. Groningen, Netherlands: s.n.

Van Der Brug, W., Fennema, M., \& Tillie, J. (2000). Anti-immigrant parties in Europe: Ideological or protest vote? European Journal of Political Research, 37(1), 77-102. https://doi.org/10.1111/1475-6765.00505

Velasco González, K., Verkuyten, M., Weesie, J., \& Poppe, E. (2008). Prejudice towards Muslims in The Netherlands: Testing integrated threat theory. British Journal of Social Psychology, 47(4), 667-685. https://doi.org/10.1348/014466608X284443

Werts, H., Scheepers, P., \& Lubbers, M. (2012). Euro-scepticism and radical right-wing voting in Europe, 2002-2008: Social cleavages, socio-political attitudes and contextual characteristics determining voting for the radical right. European Union Politics. https://doi.org/10.1177/1465116512469287

Wölfer, R., Jaspers, E., Blaylock, D., Wigoder, C., Hughes, J., \& Hewstone, M. (2017). Studying positive and negative direct and extended contact: Complementing self-reports with social network analysis. Personality and Social Psychology Bulletin, https://doi.org/10.1177/0146167217719732

Xiao, Y. J., Coppin, G., \& Van Bavel, J. J. (2016). Perceiving the world through group-colored glasses: A perceptual model of intergroup relations. Psychological Inquiry, 27(4), 255-274. https://doi.org/10.1080/1047840x.2016.1199221

Zimmerman, B. J. (2000). Self-efficacy: An essential motive to learn. Contemporary Educational Psychology, 25(1), 82-91. https://doi.org/10.1006/ceps.1999.1016

\section{Supporting Information}

Additional supporting information may be found in the online version of this article at the publisher's web site:

Appendix S1. Negative Intergroup Contact Scale/Collective Self-Efficacy Scale/Personal SelfEfficacy Scale

Appendix S2. Alternative Models

Table S2.1. Final Model Including Negative Extended Contact and Negative Vicarious Contact as Control Variables

Table S2.2. Testing the Difference Between Latent and Manifest Moderator Personal Self-Efficacy Table S2.3. Testing the Difference Between Latent and Manifest Moderator Collective Self-Efficacy 
Table S2.4. Personal Self-Efficacy Moderating the Relationship Between Negative Contact and Sociotropic Threat; Collective Self-Efficacy Moderating the Relationship Between Negative Contact and Egocentric Threat

Appendix S3. Results of Confirmatory Factor Analysis

Table S3.1. Goodness-of-Fit Statistics of Models for Sociotropic Threat, Egocentric Threat, Personal Self-Efficacy, and Collective Self-Efficacy

Appendix S4. Final Model

Table S4.1. Final Model

Appendix S5. Robustness Checks

Table S5.1. Goodness-of-Fit Statistics of the Final Structural Models and a Model with an Alternative Causal Pathway

Table S5.2. Single Items Used to Measure Existing Explanations of Radical Right-Wing Voting

Table S5.3. Additional Model Controlling for Single Items of Existing Explanations of Radical Right-Wing Voting 